\title{
EDITORIAL
}

\section{Long-term oxygen therapy in COPD patients with moderate hypoxaemia: does it add years to life?}

\author{
J. Zieliński
}

In this issue of the Journal, an ANTADIR group from France presents interesting data on survival of chronic obstructive pulmonary disease (COPD) patients receiving long-term domiciliary oxygen treatment [1]. ANTADIR is a not-for-profit organization delivering respiratory home therapy in France. This includes long-term oxygen therapy (LTOT) and mechanical ventilation for patients with chronic respiratory failure and continuous positive airway pressure (CPAP) treatment for patients with obstructive sleep apnoea syndrome. Thirty-three regional associations creating ANTADIR are responsible for the care of around $70 \%$ of all patients with chronic respiratory problems treated at home in France. Data are collected centrally resulting in the so called ANTADIR observatory. This observatory comprises thousands of patients followed up for many years.

The great advantage of analyses done by ANTADIR is that they are based on large populations of nonselected patients treated by primary care physicians giving an evaluation of how home respiratory care is applied on a national scale [2].

The Medical Research Council (MRC) [3] and nocturnal oxygen therapy trial (NOTT) [4] studies performed in the late 1970s on effects of long-term domiciliary oxygen treatment paved the way for wider use of LTOT. They were also the basis for establishing practical guidelines for prescriptions of LTOT. The widely accepted eligibility criteria for LTOT require a stable arterial oxygen tension $\left(P \mathrm{a}, \mathrm{O}_{2}\right)$ below $7.3 \mathrm{kPa}(55 \mathrm{mmHg})$. In many countries, patients with $\mathrm{Pa}, \mathrm{O}_{2}$ between $7.5-7.8 \mathrm{kPa}(56-59 \mathrm{mmHg})$ are also accepted if they present with clinical signs of cor pulmonale and elevated haematocrit.

However, it is often the case that oxygen is prescribed outside the prescription guidelines for patients with $\mathrm{Pa}, \mathrm{O}_{2}$ Š $8 \mathrm{kPa}$ ( $\breve{\mathrm{S}} 60 \mathrm{mmHg}$ ). In the commented study, Veale et al. [1] looked specifically at that group of patients. During 11 yrs of follow-up they found that $18.5 \%$ out of 7,700 COPD patients qualified for LTOT presented, at entry,

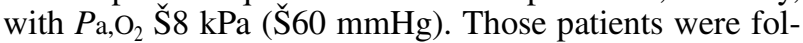
lowed up, and their survival was compared with the survival in patients with $\mathrm{Pa}, \mathrm{O}_{2}<8 \mathrm{kPa}(<60 \mathrm{mmHg})$ at entry. Somewhat surprisingly, there was no difference in the survival rate between both groups.

Patients with $\mathrm{Pa}_{2} \mathrm{O}_{2}$ Š $8 \mathrm{kPa}$ ( $\breve{\mathrm{S}} 60 \mathrm{mmHg}$ ) were characterized by lower arterial carbon dioxide tension $\left(P \mathrm{a}, \mathrm{CO}_{2}\right)$ and more frequent clinical signs of emphysema compared with patients with $\mathrm{Pa}, \mathrm{O}_{2}<8 \mathrm{kPa}$ ( $<60 \mathrm{mmHg}$ ). The other inter-

Correspondence: J. Zieliński, Dept of Respiratory Medicine, Institute of Tuberculosis and Lung Diseases, Plocka 26, 01-138 Warsaw, Poland. Fax: 48226912454 esting finding was that despite large individual variations in $\mathrm{Pa}, \mathrm{O}_{2}$ in the studied patients ranging $4-10.6 \mathrm{kPa}(30$ $80 \mathrm{mmHg}$ ), their forced expiratory volume in one second (FEV1) was severely reduced to $32 \pm 13 \%$ of predicted.

The authors conclude that the survival of patients with a $\mathrm{Pa}_{\mathrm{a}, \mathrm{O}_{2}} \mathrm{\textrm {S }} 8 \mathrm{kPa}$ ( $\check{\mathrm{S}} 60 \mathrm{mmHg}$ ) prescribed LTOT is similar to the survival of more hypoxaemic patients also treated with LTOT. As their study was observational, the authors suggest that a controlled study on LTOT in such patients is warranted.

Such a study was performed and recently published. GóRECKA et al. [5] conducted a randomized clinical trial on the effects of LTOT on survival in COPD patients with moderate hypoxaemia. They studied 135 COPD patients referred for LTOT, with a stable $P \mathrm{a}, \mathrm{O}_{2}$ ranging $7.4-8.7 \mathrm{kPa}$ (56-65 $\mathrm{mmHg})$ measured twice at least 3 weeks apart. The group was randomly divided into a LTOT group (68 patients) and a control group not receiving oxygen (67 patients). All patients were closely followed up for at least 3 yrs. There was no difference in age, sex, body mass index, haematocrit, vital capacity (VC), FEV1 and $\mathrm{Pa}_{\mathrm{a}} \mathrm{CO}_{2}$ between LTOT and control groups. The mean $P \mathrm{a}, \mathrm{O}_{2}$ was $7.9 \pm 0.4 \mathrm{kPa}(59.5 \pm 2.7 \mathrm{mmHg})$ in the LTOT group and $8.2 \pm 0.4 \mathrm{kPa}(61.3 \pm 2.7 \mathrm{mmHg})$ in the control group.

The severity of airways obstruction in the patients studied by GóRECKA et al. [5] (mean FEV1 29.8 $\pm 9.8 \%$ pred) was very similar to the severity of airway obstruction in patients studied by VEALE et al. [1] (32.2 $\pm 13.2 \%$ pred).

Seventy patients died during the observation period: 32 in the control group and 38 in the LTOT group. Most of the deaths were due to progression of COPD. There was no difference in the survival rates between patients receiving LTOT and controls. Better survival was significantly related to younger age, higher FEV 1 and higher body mass index.

The mean oxygen breathing hours was $13.5 \mathrm{~h} \cdot$ day $^{-1}$, which was less than the suggested prescription demanding at least $15 \mathrm{~h} \cdot$ day $^{-1}$. However, further analysis showed that nonsurvivors were using oxygen longer than survivors $(14.2 \mathrm{~h})$ and that patients who used oxygen for $>15 \mathrm{~h} \cdot$ day $^{-1}$ had no better survival than patients who used less oxygen.

The data of GóRECKA et al. [5] suggest that LTOT fails to prolong life not only in patients with $\mathrm{Pa}_{2} \mathrm{O}_{2}>8 \mathrm{kPa}(>60$ $\mathrm{mmHg})$, but also in patients with $\mathrm{Pa}_{\mathrm{a}_{2}}>7.3 \mathrm{kPa}(>55$ $\mathrm{mmHg}$ ).

Both papers suggest a more cautious approach to prescription of LTOT in patients with moderate hypoxaemia. LTOT is expensive, cumbersome and imposes important restraints on daily activities of patients. Such treatment should not be prescribed too early in the natural course of 
the disease. This opinion is valid only if we take longevity of life as an end point. There is still no data on how LTOT may influence the quality of life in those patients.

Both papers confirm that the best predictor of survival in COPD patients seems to be FEV1 [6, 7]. Before the LTOT era, $\mathrm{Pa}_{\mathrm{a}} \mathrm{O}_{2}$ [8] or arterial oxygen saturation $\left(\mathrm{Sa}_{\mathrm{a}} \mathrm{O}_{2}\right)$ [9] and pulmonary arterial pressure [10] were also very good predictors of survival. As all these variables are interrelated, it is difficult to ascertain primary and secondary effects of any of them.

Oxygen supplementation, although not continuous in practice, seems to alleviate some signs of chronic hypoxia such as elevated haematocrit and progression of pulmonary hypertension [3]. In a recent study by our group [11], we have shown that LTOT in COPD patients stabilizes pulmonary arterial pressure over 6 yrs of treatment, despite important falls in $\mathrm{Pa}, \mathrm{O}_{2}$ and increases in $\mathrm{Pa}_{\mathrm{a}}, \mathrm{CO}_{2}$ during that long period of time.

The mechanisms by which LTOT prolongs life are still not known. It would by very simplistic to believe that a control of polycythaemia and of pulmonary hypertension are the only factors.

Why does LTOT not prolong life in patients with moderate hypoxaemia? One may speculate that it is most likely because it is not necessary and does not influence the natural course of the disease. A $P \mathrm{a}, \mathrm{O}_{2}$ close to or above 8 $\mathrm{kPa}(60 \mathrm{mmHg})$ lies on the horizontal part of the oxyhaemoglobin dissociation curve. This assures satisfactory oxyhaemoglobin saturation and sufficient oxygen transport protecting from chronic tissue hypoxia. However, it does not stop the progression of airway obstruction [11, 12].

The majority of those patients, despite satisfactory arterial blood gases, present with severe airway obstruction. The patients of both GórecKa et al. [5] and Veale et al. [1] had an FEV1 only around $30 \%$ of the predicted. It is worth noting that among the ANTADIR patients, a sig- nificant proportion presented with a clinical picture of emphysema. The lungs of such patients are usually hyperinflated with intrinsic positive end-expiratory pressure (PEEP) $[13,14]$. The work of breathing is increased $[15,16]$. One may speculate that during disease exacerbation, which seems to be the most frequent cause of death in COPD [17], some of those patients may die due to respiratory muscle fatigue [18]. Modern techniques of evaluation of the diaphragmatic function [19] should provide data to address such a hypothesis.

Another point of the paper of Veale et al. [1] deserves further comment. In the discussion section, the authors suggest that LTOT was prescribed to their patients with $P \mathrm{a}, \mathrm{O}_{2}>8 \mathrm{kPa}(>60 \mathrm{mmHg}$ ) for nocturnal desaturations or desaturations on exercise.

According to many national guidelines for LTOT, to qualify a patient for nocturnal oxygen therapy, an overnight pulse oximetry is mandatory. The criteria differ from country to country. In Belgium, the $\mathrm{Sa}_{\mathrm{a}} \mathrm{O}_{2}$ should drop during sleep below $88 \%$ for at least $1 \mathrm{~h}$, and this phenomenon should be accompanied by clinical signs: elevated haematocrit, signs of cor pulmonale and neuropsychological deficits. In Austria, $\mathrm{Sa}_{2} \mathrm{O}_{2}$ should drop below $75 \%$, and obstructive sleep apnoea syndrome should be excluded. In the Netherlands, $\mathrm{Sa}_{\mathrm{a}} \mathrm{O}_{2}$ should be $<90 \%$ for at least $2 \mathrm{~h}$. In the UK and Portugal, the mean $\mathrm{Sa}_{\mathrm{a}} \mathrm{O}_{2}$ should be below $90 \%$ for at least one-third of the night. In the USA, the mean overnight $\mathrm{Sa}_{\mathrm{a}} \mathrm{O}_{2}$ should stay below $88 \%$.

The rationale for nocturnal oxygen supplementation is based on clinical observations that many COPD patients with a satisfactory $\mathrm{Pa}, \mathrm{O}_{2}$ while resting and awake desaturate during sleep, especially during rapid eye movement (REM) sleep [20, 21]. It was suggested that nocturnal desaturations may precipitate the development of cor pulmonale [22, 23]. Although consecutive investigations by FLeTCHER et al. [21, 24, 25] seemed to support such a hypothesis, more recent studies by СНаолат et al. [26] did not confirm that patients who desaturate during sleep present with higher pulmonary arterial pressure, than wellmatched patients who do not desaturate during sleep. There is one study suggesting improved survival in "desaturators" treated with oxygen compared with "desaturators" from the control group [27]. However, the preliminary re-sults of the study by CHAолат et al. [28] did not confirm that observation.

The two papers, by Veale et al. [1] and GórecKa et al. [5] also do not confirm benefits of the overnight oxygen supplementation in patients with moderate hypoxaemia. Around one-third of COPD patients with satisfactory oxygenation during the day desaturate overnight [21]. One may assume that such patients were also included in both studies mentioned above and that they were breathing oxygen during sleep. However, oxygen did not improve their survival. Although the above evidence does not confirm benefits of nocturnal oxygen supplementation in patients with moderate hypoxaemia further controlled study on the use of that modality of treatment is needed.

The effects of oxygen supplementation to prevent desaturations during exercise are also far from being elucidated. There are several studies showing improvement in exercise tolerance during an acute administration of supplemental oxygen [29, 30]. However, the improvement was not related to prevention of hypoxaemia [29] but rather to reduction of breathlessness $[29,30]$.

It is well known that breathlessness during exercise correlates with airflow limitation rather than with $P \mathrm{a}, \mathrm{O}_{2}$. The improvement in exercise performance with oxygen is related to the ability of performing higher amounts of work with the same maximal minute ventilation rather than with prevention of desaturation $[31,32]$. However, data on long-term effects of oxygen supplementation during physical efforts in patients with moderate hypoxaemia are lacking and would be very difficult to perform.

It seems that for the question "does long-term oxygen therapy add years to life in patients with moderate hypoxaemia?", the answer is "no". The important question "does it add life to years?" remains unanswered. We are still awaiting controlled studies on long-term oxygen therapy in that specific group of patients with a health-related quality of life assessment as a primary end point.

\section{References}

1. Veale D, Chailleux F, Taytard A, Cardinaud JP. Characteristics and survival of patients prescribed long term oxygen therapy outside prescription guidelines. Eur Respir $J$ 1998; 12: 780-784.

2. Chailleux F, Fauroux B, Binet F, Dautzenberg B, Polu JM. Predictors of survival in patients receiving domiciliary oxygen therapy or mechanical ventilation. A 10-years 
analysis of ANTADIR observatory. Chest 1996; 109: 741-749.

3. Medical Research Council Working party. Long-term domiciliary oxygen therapy in chronic hypoxic cor pulmonale complicating chronic bronchitis and emphysema. Lancet 1981; 1: 681-686.

4. Nocturnal oxygen therapy trial group. Continuous or nocturnal oxygen therapy in chronic obstructive pulmonary disease. A clinical trial. Ann Intern Med 1980; 93: 391398.

5. Górecka D, Gorzelak K, Śliwiński P, Tobiasz M, Zieliński J. Effect of long term oxygen therapy on survival in patients with chronic obstructive pulmonary disease with moderate hypoxaemia. Thorax 1997; 52: 674-679.

6. Kanner RE, Renzetti AD, Stanish WM, Barkman HW, Klauber MR. Predictors of survival in subjects with chronic airflow limitation. Am J Med 1983; 74: 249-255.

7. Anthonisen NR, Wright EC, Hodgkin JE. Prognosis in chronic obstructive pulmonary disease. Am Rev Respir Dis 1986; 133: 14-20.

8. Physiological variables and mortality in patients with various categories of chronic respiratory disease. WHO multicentre study. Bull Eur Physiopathol Respir 1984; 20: 495-500.

9. Bishop JM. Hypoxia and pulmonary hypertension in chronic bronchitis. Progr Respir Res 1975; 9: 10-16.

10. Ourednik A, Suza Z. How long does the pulmonary hypertension last in chronic obstructive bronchopulmonary disease. Progr Respir Res 1975; 9: 24-30.

11. Zieliński J, Tobiasz M, Hawryłkiewicz I, Śliwiński P, Pałasiewicz G. Effects of LTOT on pulmonary hemodynamics in COPD patients: a six year prospective study. Chest 1998; 113: 65-70.

12. Cooper CB, Howard P. An analysis of sequential physiologic changes in hypoxic cor pulmonale during long-term oxygen therapy. Chest 1991; 100: 76-80.

13. Hałuszka J, Chartrand DA, Grassino AE, Milic-Emili J. Intrinsic PEEP and arterial $P_{\mathrm{a}}, \mathrm{CO}_{2}$ in stable patients with chronic obstructive pulmonary disease. Am Rev Respir Dis 1990; 141: 1194-1197.

14. Yan S, Kayser B, Tobiasz M, Sliwiński P. Comparison of static and dynamic intrinsic positive end-expiratory pressure using the Campbell diagram. Am J Respir Crit Care Med 1996; 154: 938-944.

15. Coussa ML, Guerin C, Eissa NT, et al. Partitioning of work of breathing in mechanically ventilated COPD patients. J Appl Physiol 1993; 75: 1711-1719.

16. Śliwiński P, Kamiński D, Zieliński J, Yan S. Partitioning of elastic work of inspiration in COPD patients during incremental exercise. Eur Respir J 1997; 10: Suppl. 25, 247s (abstract).

17. Zieliński J, MacNee W, Wedzicha J, et al. Causes of death in patients with COPD and chronic respiratory failure. Monaldi Arch Chest Dis 1997; 52: 43-47.

18. Sliwiński P, Macklem PT. Inspiratory muscle dysfunction as a cause of death in COPD patients. Monaldi Arch Chest Dis 1997; 52: 380-383.

19. Sinderby C, Lindstrom L, Grassino AE. Automatic assessment of electromyogram quality. J Appl Physiol 1995; 79: $1803-1815$.

20. Douglas NJ, Calverley PMA, Leggett RJE, Brash HM, Brezinova V. Transient hypoxaemia during sleep in chronic bronchitis and emphysema. Lancet 1979; 1: 1-4.

21. Fletcher EC, Miller J, Devine J, Fletcher J, Miller T. Nocturnal oxyhemoglobin desaturation in COPD patients with arterial oxygen tensions above $60 \mathrm{mmHg}$. Chest 1987; 92: 604-608.

22. Flenley DC. Clinical hypoxia: causes, consequences and correction. Lancet 1978; 1: 542-546.

23. Block AJ, Boysen PG, Wynne JW. The origins of cor pulmonale. A hypothesis. Chest 1979; 75: 109-110.

24. Fletcher EC, Luckett RA, Miller T, Fletcher JG. Exercise hemodynamics and gas exchange in patients with chronic obstructive pulmonary disease, sleep desaturation and daytime $P_{\mathrm{a}, \mathrm{O}_{2}}$ above $60 \mathrm{mmHg}$. Am Rev Respir Dis 1989; 140: 1237-1245.

25. Fletcher EC, Luckett RA, Goodnight-White S, et al. A double-blind trial of nocturnal supplemental oxygen for sleep desaturation in patients with chronic obstructive pulmonary disease and daytime $\mathrm{Pa}, \mathrm{O}_{2}$ above $60 \mathrm{mmHg}$. $\mathrm{Am}$ Rev Respir Dis 1992; 145: 1070-1076.

26. Chaouat A, Weitzenblum E, Kessler R, et al. Sleep related $\mathrm{O}_{2}$ desaturation and daytime pulmonary haemodynamics in COPD patients with mild hypoxaemia. Eur Respir J 1997; 52: 674-679.

27. Fletcher EC, Donner CF, Midgren B, Zieliński J, LeviValensi P. Survival in COPD patients with daytime $\mathrm{Pa}_{\mathrm{a}} \mathrm{O}_{2}$ $>60 \mathrm{mmHg}$ with or without nocturnal oxygen desaturation. Chest 1992; 101: 649-655.

28. Chaouat A, Charpentier C, Kessler R, et al. A trial of nocturnal $\mathrm{O}_{2}$ therapy (NOT) in chronic obstructive pulmonary disease (COPD). Am J Respir Crit Care Med 1998; 157: A803.

29. Bradley BL, Gamer AE, Billin D, Mestar JM, Forman J. Oxygen-assisted exercise in chronic obstructive lung disease. Am Rev Respir Dis 1978; 118: 239-243.

30. Woodcock AA, Gross ER, Geddes DM. Oxygen relieves breathlessness in pink puffers. Lancet 1981; 1: 907-909.

31. Davidson AC, Leach R, George RJD, Geddes DM. Supplemental oxygen and exercise ability in chronic obstructive airways disease. Thorax 1988; 43: 965-971.

32. Stein DA, Bradley BL, Miller WC. Mechanisms of oxygen effects on exercise in patients with chronic obstructive pulmonary disease. Chest 1982; 81: 6-10. 